\title{
Out for coffee: with Rob
}

\section{Ansgar Fehnker ${ }^{1}$}

Received: 21 February 2020 / Accepted: 24 February 2020 / Published online: 6 May 2020

(c) The Author(s) 2020

\begin{abstract}
I have known Rob van Glabbeek as a colleague for 16 years, of which eight years were in the same research group. However, this only amounts to less than half of his professional life which started in the mid-1980s at the Centrum voor Wiskunde en Informatica in Amsterdam. In this article, I am trying to piece together the information I got from colleagues as well as from Rob himself - to the best of my recollection - to give an insight into Rob as a colleague, researcher, and person.
\end{abstract}

I joined NICTA in November 2004, about half a year after Rob. As a student of Frits Vaandrager, I knew Rob's name, and not just because it is a household name in the Dutch computer science community. When I was visiting Stanford for a week as a student in the late 1990s, Frits' principal advice was that to make most of my short visit I should look out for Rob. Which I didn't.

NICTA had been founded two years earlier as a joint project of several Australian universities. Initially, most NICTA researchers were employed by a host institute and then seconded to NICTA. Rob and I were in the first generation of researchers employed directly by NICTA itself. We were both members of the Formal Methods research group, a small group of likeminded researchers, with Rob the most senior new arrival. In the first year, our group was housed on a spare floor of the chemical engineering building, with frequent fire alarms a reminder that we were among chemical engineers.

Not only because the different groups of NICTA were spread out over multiple buildings on UNSW campus, there was an established practice to go out for coffee, go out for lunch, and frequently finish the week at "beer o'clock" at one of the nearby hotels (which is the Australian term for a pub or bar), where Rob' usually had a cider. These traditions continued when we later moved with all other NICTA groups into a newly built modern office building on the edge of campus, with cubicles, glass offices, social spaces and the lot.

During these occasions - out for coffee-we covered all types of topics, especially about the new environment we found ourselves in. This contribution for the Festschrift relies on what I remember of what Rob told us during these occasions. I got to know him as a careful and original thinker, on all aspects of research and life.

One aspect of working at NICTA was how to deal with a budding bureaucracy that tried to establish itself. This included, for example, that we were sent detailed instructions on the correct use of the officially approved colour scheme in printed and electronic communications

Ansgar Fehnker

ansgar.fehnker@utwente.nl

1 University of Twente, Enschede, The Netherlands 
as well as engravings, and importantly the correct placement of the new logo, especially in relation to logos of other organisations. Confronted with a detailed specification, we spent, of course, many coffee breaks discussing the internal consistency and feasibility of that document from the communications department. Equally interesting were the instructions sent to all researchers on the proper use of email. This was not a minute too late given that all of us we had written emails since the dawn of the internet as we know it - and without any proper training at all. At these times Rob liked to remind us that when he started life as a computer scientist in the Netherlands punch cards were still in use.

Rob was a master student in Mathematics in Leiden in the early 1980s and a PhD student at CWI from 1984 to 1989. This was a time when in many places the computer science groups in either mathematics or philosophy formed their own departments. The Mathematisch Instituut had just in 1983 changed its name to Centrum voor Wiskunde en Informatica (Center for Mathematics and Computer Science).

At CWI Rob was part of a small group of students who worked under the supervision of Jan Bergstra. This group was known for its work on the Algebra of Communicating Processes (ACP), which was proposed by Jan Bergstra and Jan-Willem Klop in the early 1980s. Characteristic of that group was, that it was a place to freely share ideas and discuss problems. Rob, in particular, stood out as a person who seriously engaged with the work of others. Rob would often make notes, work out a solution, and store them in his drawer. It would frequently happen that when someone presented a problem, Rob already had a note in his drawer, with a worked-out solution.

An anecdote, not about Rob himself, but about Frits Vaandrager - Robs office mate and sparring partner-illustrates life at CWI. At one occasion, Frits openly expressed delight at the fact they were talking about their work all the time. Unlike other less fortunate people, they did not feel the need to talk about sports or politics during their coffee breaks. They talked about what they loved most, process algebra, and were fortunate enough to do this for a living too ${ }^{1}$. This was a very productive research group that to the surprise of visitors only comprised about half a dozen people, instead of the dozens they expected.

Whenever we discussed at NICTA the latest guideline on the use of information technology, Rob usually breathed a sigh of relief that he could still use-and still uses today-his Stanford email address as his main address. His time in Stanford takes a central place in Rob's life. Rob stayed there from 1991 until 2003 and lived through the run-up, peak, and aftermath of the dot-com bubble (Fig. 1).

Wan Fokkink, who visited Rob at Stanford, reported that Rob had an extensive social network with important and colourful figures, respected researchers, and tech entrepreneurs, some of them not quite evil, and living the best life that California and the Bay Area had to offer. Rob often referred to his Stanford experience - and not just that he enjoyed that the Californian weather was almost disappointingly predictable. An outward sign of the importance of Stanford for Rob is that not just his email, but also his server, the central hub for his work, is still situated in Stanford.

Even though NICTA was bringing together different types of researchers and professionals with different attitudes and backgrounds, it worked surprisingly well. This was mostly due to a display of constructive indifference. The different groups and researchers were playing along and continued doing what they did best. In the case of Rob, it meant continuing his research. Initially, he mostly worked with colleagues from all over the world. From his CWI

\footnotetext{
${ }^{1}$ Later talking about process algebra during breaks must have been too much fun even for CWI, and it is reported that there was a fine of $f 1$ (approximately EUR 1 after inflation) if someone was caught talking about work during breaks.
} 


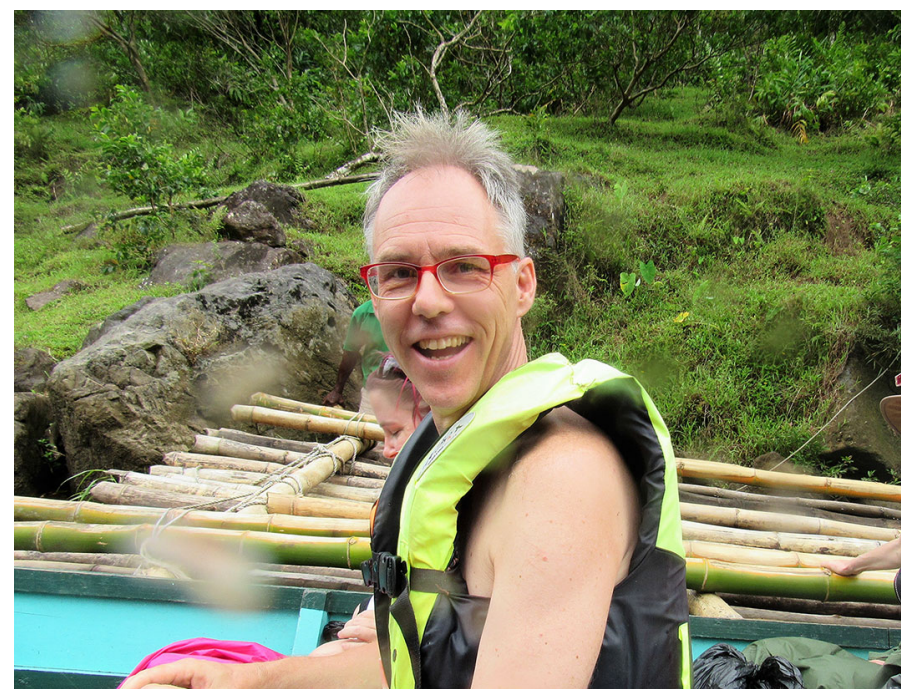

Fig. 1 Robert van Glabbeek, just minutes before taking a plunge into the Navua River

and Stanford days, but also from his journeyman year between leaving Stanford, and settling in Syndey, when he spent short periods at different research institutions all over the world.

Whenever there was a need for a speaker at a colloquium, Rob offered to give a talk, often stating that he always had something in his drawer. This was a habit apparently going back to the PAM, the seminar at CWI. This drawer was also the source of research topics for students at NICTA, another habit that went back for a long time. Wan told me, for example, that when he first mentioned his interest in congruence, Rob opened his drawer to get an A4 piece of paper with a research idea that formed the basis of their LICS 2000 paper [1]. If you want to generate precongruence formats from modal logic characterisations of process semantics, then there is a real chance that there is something in Rob's drawer about it.

Besides research, Rob used the considerable freedom he enjoyed at NICTA to create EPTCS, and open access publisher for theoretical computer science. He built a fully-fledged submission and reviewing system, that in all details shows signs of Rob's hand. As a libertarian, not just in the political sense, Rob values the free exchange of ideas. And in his area, this means to write and publish papers. Reportedly, when Rob was a PhD student at CWI he was content to keep his ideas in his drawer ... until Jan Bergstra intervened and told him that he could not claim the solution to a problem unless it was published. After this, Rob published many papers in quick succession.

NICTA's mission was to conduct use-inspired research [6]. A series of successive useinspired research projects proposed the use of formal methods for the analysis of wireless networks. These were initiated by Annabelle McIver, Athanassios Boulis and me, and eventually included Peter Höfner, Marius Portmann, Wee Lum Tan and of course Rob.

At first, when I travelled and former colleagues asked about Rob's whereabouts in Australia, they usually looked rather concerned when I told them that Rob was part of a project on wireless networks, only to show a sign of relief once I told them that he was working, of course, an algebra for wireless networks. Which later became AWN [2].

Working with Marius Portmann and Wee Lum Tan from the Queensland lab was particularly fruitful. They came from the NICTA "theme" Networked Systems and had the patience 
to explain to us, from the "theme" Managing Complexity, in white-board sessions, how to read the RFC for the AODV protocol. If you have ever worked with Rob you would have noticed that Rob wants to get to the bottom of a concept or idea and fully understand it. And understanding means, being able to formalise it properly.

The most basic property of a routing algorithm like AODV is that it should be loop-free. Almost all documentation on the protocol stated prominently that the protocol was indeed loop-free, but the reasoning usually amounted to not much more than "because: sequence numbers". One day, while I was busy attempting to express the various versions of loop freedom in Uppaal, I was interrupted by Peter. Peter and Rob asked me to have a look at their whiteboards and proudly presented a counter-example to the self-evident truth that AODV was loop-free. Apparently, it was not [3]. It very rarely happens that you meet happier computer scientists than Rob discovering a counter-example.

And of course, while many scientists would have been content with proving that AODV is not loop-free, Peter and Rob investigated all the different interpretations of AODV, and their implementations, to fully understand the relationship between sequence numbers and loop-freedom. Unfortunately, I was not present when they managed to conclude the proof.

Jan Friso Groote was lucky to be an eyewitness to the discovery of branching bisimulation. Jan Friso was at the time a junior PhD student in Jan Bergstra's group compared to Rob and learned to appreciate that Rob always pointed out the flaws in his ideas [5]. Peter Weijland, also a PhD student at CWI, worked on the problem of observational equivalence of the branching structure of processes. As was customary in the group, Peter shared this and the problems he faced with his colleagues. Rob and Peter discussed the problem one summer's day in 1988 (?) on the veranda of CWI. The veranda still exists, although it is now a bit smaller. Writing with a pebble on the pavement they both identified the problem and worked out the solution: all in one sunny afternoon. This later became is the foundation of their seminal paper Branching time and abstraction in bi-simulation semantics [4]. Jan Friso's and I share the assessment that if you want to gain deeper insight into a problem, it is a good idea to discuss it with Rob. He is unique in his ability to get to the core of an idea.

After I left NICTA, Rob and I still were in contact, in part to finalise some work on the analysis of wireless networks. Rob also visited the University of Twente to teach a course on formal methods for wireless networks. After some introductory lectures, this course mainly consisted of him and the students spending the afternoon with an RFC of some protocol, his algebra for wireless networks, and a white-board, trying to understand the core idea of the protocol. For students this was a valuable experience, especially understanding the importance of using the right formalism.

The final anecdote of this contribution happened earlier, during LPAR 20, which took place 2015 in Fiji. The social event included a boat ride up the Navua River, towards an inland waterfall, and subsequent descent by a raft down the river, and then and a cultural presentation in a Fijian village. Rob and Geoff Sutcliffe were the first people I saw jumping off the boat to take a plunge in the river. I have rarely seen any theoretical computer scientist have so much blissful fun. Probably comparable to the joy of finding a counterexample, and maybe only dwarfed by the joy of completing a proof.

Over the last weeks, I talked to many colleagues about Rob and what they remember. There are many anecdotes to tell, about his car, and what happened to it, about how to beat the traffic in Watergraafsmeer, and what he would do if in a coma (spoiler: process algebra). What strikes me most about Rob is his commitment to people, and by extension, to communities. You see this when you look at the list of his coauthors, many of who have worked with him for decades, his fairly regular annual schedule that includes among others his favourite conferences like CONCUR, his skiing holidays with friends, and the Burning 
Man festival. Or his server in Stanford. And Rob is unique in combining all this commitment with an open and inquisitive mind.

Acknowledgements I'd like to thank all colleagues who provided me input, in particular, Jan Friso Groote and Wan Fokkink, who gave valuable insight about Rob's time before NICTA.

Open Access This article is licensed under a Creative Commons Attribution 4.0 International License, which permits use, sharing, adaptation, distribution and reproduction in any medium or format, as long as you give appropriate credit to the original author(s) and the source, provide a link to the Creative Commons licence, and indicate if changes were made. The images or other third party material in this article are included in the article's Creative Commons licence, unless indicated otherwise in a credit line to the material. If material is not included in the article's Creative Commons licence and your intended use is not permitted by statutory regulation or exceeds the permitted use, you will need to obtain permission directly from the copyright holder. To view a copy of this licence, visit http://creativecommons.org/licenses/by/4.0/.

\section{References}

1. Bloom, B., Fokkink, W., van Glabbeek, R.: Precongruence formats for decorated trace preorders. In: Proceedings 15th Annual IEEE Symposium on Logic in Computer Science (Cat. No.99CB36332), pp. 107-118 (2000). https://doi.org/10.1109/LICS.2000.855760

2. Fehnker, A., van Glabbeek, R., Höfner, P., McIver, A., Portmann, M., Tan, W.L.: A process algebra for wireless mesh networks used for modelling, verifying and analysing AODV (2013). arXiv:1312.7645

3. van Glabbeek, R., Höfner, P., Tan, W.L., Portmann, M.: Sequence numbers do not guarantee loop freedom: AODV can yield routing loops

4. van Glabbeek, R.J., Weijland, W.P.: Branching Time and Abstraction in Bisimulation Semantics. J. ACM 43(3), 555-600 (1996). https://doi.org/10.1145/233551.233556

5. Groote, J.F.: Process algebra and structured operational semantics. Ph.D. thesis, Universiteit van Amsterdam (1991). https://www.win.tue.nl/ jfg/articles/proefschrift.pdf

6. Seneviratne, A., Percival, T.: National ICT Australia (NICTA). SIGCOMM Comput. Commun. Rev. 35(3), 61-64 (2005). https://doi.org/10.1145/1070873.1070880

Publisher's Note Springer Nature remains neutral with regard to jurisdictional claims in published maps and institutional affiliations. 